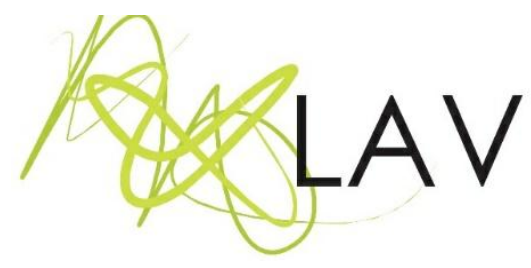

\title{
A poiésis Dilaporal: formação estética docente e performance art
}

The Bodilation poiesis: teacher aesthetic education and performance art

\author{
Pedro Gottardi \\ Universidade Regional de Blumenau \\ Carla Carvalhoi \\ Universidade Regional de Blumenau
}

\begin{abstract}
Resumo
O presente artigo teve por temática a poiésis, a performance art e a formação estética docente. O objetivo foi investigar processos poéticos no qual o corpo do pesquisador também fosse tema e suporte na poiésis, relacionando à/aos artistas Marina Abramović, Hélio Oiticica e Artur Barrio e a suas obras. De abordagem qualitativa, o percurso metodológico abarcou a Pesquisa Educacional Baseada em Arte (DIAS; IRWIN, 2013) e a matriz a/r/tográfica, organizada em levantamento bibliográfico, aprofundamento teórico, percurso poético e visualidades. Barthes (2018) norteou a análise da investigação, em que o studium perpassou a formação docente, garimpando estesias que foram absorvidas na poíesis em forma de punctum. Os resultados apresentam quatro obras que compõem a série Dilaporal. Conclui-se que as visualidades poetizadas são como garimpagens do a/r/tógrafo na formação estética docente.
\end{abstract}

Palavras-chave: Artes Visuais, corpo, Dilaporal, formação estética docente, performance art.

\begin{abstract}
The present paper discusses poiesis, performance art and teacher aesthetic education. It aims at investigating poetic processes in which the researcher's body is also theme and support in poiesis, relating them to the artists and works of Marina Abramović, Hélio Oiticica and Artur Barrio. With a qualitative approach, the methodological path covered the ArtsBased Education Research (DIAS; IRWIN, 2013) and the a/r/tographic matrix, organized in bibliographic survey, theoretical framework, poetic path, and visualities. Barthes (2018) guided the analysis of the investigation, where the studium went through teacher education, digging aesthesias that were absorbed in the poiesis in the form of punctum. The results present four works that make up the Bodilation series. Results indicate that the poetized visualities are related to the a/r/tographer's digging in the aesthetic teacher education.
\end{abstract}

Keywords: Visual Arts, body, Bodilation, teacher aesthetic education, performance art. 


\section{um - primeiros passos} Em movimento antropofágico o corpo[CARNE] questiona sua existência.
Vermelho, arbitrário. Manifesta suas inquietações.

(Pedro Gottardi, 2018)

O maior desafio de cada criador é traçar seu próprio percurso na relação com seu corpo e sua subjetividade, tendo a poetização como alternativa para a recriação de si mesmo e da descoberta das potencialidades do corpo. Não há lugar mais político do que o corpo. Por que não deixar um corpo falar poeticamente suas emoções ao perceber o desejo pela arte? A vida, como bom campo fértil, pode proporcionar experiências estéticas, dissolvidas em vivências reconhecidas pelo próprio corpo na arte; neste caso, vivências poéticas de um artista/pesquisador/professor.

Disposto no espaço de sua casa, o artista separou uma câmera fotográfica, um tripé, pedaços de carne bovina, linha de algodão e agulha e desnudou-se. Em um primeiro momento, o corpo construiu uma máscara com os pedaços de carne; logo, usou-a, criou poses e descartou-a. Esse ato deu vida ao processo poético registrado pela luz no filme fotográfico, e o acontecimento revelou-se ao mundo.

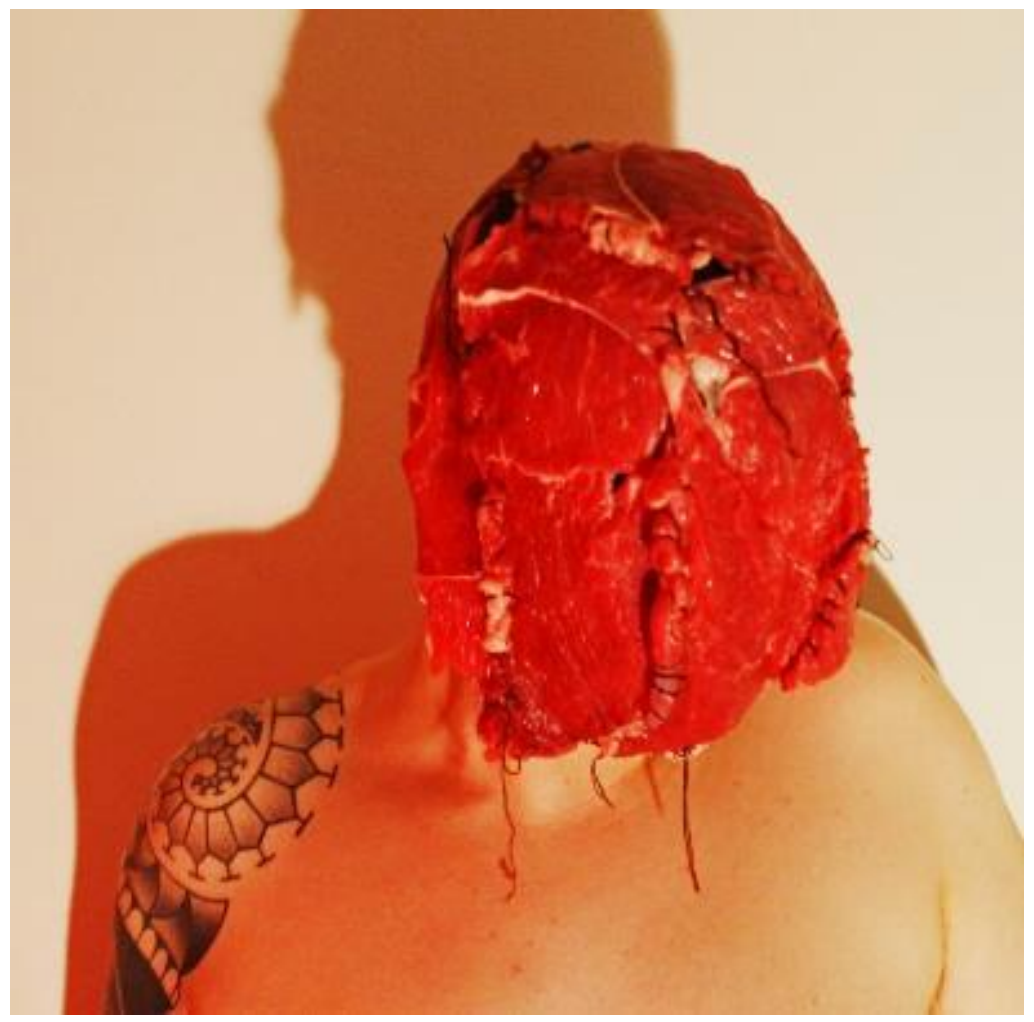

Figura 01: Obra que compõe a série Dilaporal | Técnica: Performance, fotografia e edição gráfica | Suporte: Tecido | Dimensões: $50 \times 50 \mathrm{~cm}$ | Ano: 2018

Fonte: Pedro Gottardi, 2018 
Dilaporal. Na Figura 01, observamos o corpo do artista/pesquisador/professor que realiza essa investigação como tema e suporte em performance, registrado por meio de uma lente fotográfica, utilizando o mecanismo timer. Esta escrita acontece ao perceber-se a investigação de Barthes (2018, p. 14), para o qual a fotografia "repete mecanicamente o que nunca mais poderá repetir-se existencialmente", junto à vontade de falar sobre um corpo arbitrário, de carne na cor vermelha, que, de algum modo, manifesta suas inquietações na poiésis. A máscara de carne bovina, costurada com fio de algodão, esconde a imagem da face de um corpo que procura compreender sua existência, de um estudante de graduação em seu percurso de formação docente em Licenciatura em Artes Visuais. A carne bovina é selecionada por sua facilidade de compra, seu consumo sem a preocupação de sua procedência, sem conhecer a trajetória do rito de criação do animal ao empacotamento no comércio. A máscara é confeccionada com o objetivo de esconder a face daquele que a usa e conectá-lo aos signos da carne, do mamífero, do encontro da similaridade, reconstruída como forma de elucidar o que há por baixo da pele.

Exploramos aqui a formação estética docente, tendo o corpo como potência criativa. Objetivamos pesquisar o corpo desse artista/pesquisador/professor como tema e suporte na arte, tecendo relações, no processo poético, com a/os artistas Marina Abramović, Hélio Oiticica e Artur Barrio. Nosso desejo de pesquisa anseia por estudos nos quais a arte transborde os conceitos teóricos para, assim, revelar visualidades do corpo durante a pesquisa, vinculada a aproximações de artistas que laboram o corpo na contemporaneidade. "Desde o Body art"1, a utilização do corpo, tanto pela arte como pela publicidade, vem assinalando um importante crescimento e uma expressiva diversificação" (PIRES, 2005, p. 87).

Este estudo está vinculado ao Grupo de Pesquisa Arte e Estética na Educação (GPAEE) da Linha de Pesquisa Linguagens, Arte e Educação, vinculado ao Programa de Pós-Graduação em Educação da Universidade Regional de Blumenau (FURB). O grupo investiga as relações entre arte, estética e educação, discute sobre as formas de interação dos sujeitos a partir de manifestações da arte e busca compreender processos de mediação cultural e educação estética.

O percurso metodológico abarca a Pesquisa Educacional Baseada em Arte (PEBA) (DIAS; IRWIN, 2013). De abordagem qualitativa, esta investigação olha para o percurso de um artista/pesquisador/professor em processo de formação, por isso busca, na $A / r /$ tografia, potência e possibilidades de diálogos metodológicos. "A/R/T é uma metáfora

\footnotetext{
${ }^{1}$ Bodyart ou arte do corpo caracteriza uma forma de expressão artística em que o artista se coloca como obra, usando seu corpo como suporte (PIRES, 2005).
} 
para: Artist (artista), Researcher (pesquisador), Teacher (professor) e graph (grafia: escrita/representação)" (DIAS, 2013, p. 25). O a/r/tógrafo assume-se como artista/pesquisador/professor; também reclama o saber e o fazer arte e educação para justapor metodologias de pesquisa, produzindo arte no percurso da pesquisa. Essa metodologia permite-nos relacionar nossos estudos à produção em arte. Reconhecemos que esse campo metodológico foge a padrões quantitativos para dar vazão às subjetividades do sujeito que realiza pesquisas educacionais em arte.

Pesquisadores que se utilizam da PEBA exploram "modos criativos de representação que reflitam a riqueza e a complexidade das amostras e dados de pesquisa e desse modo promovem múltiplos níveis de envolvimento, que são simultaneamente cognitivos e emocionais" (DIAS, 2013, p. 24). Isso permite que os pesquisadores explorem "a compreensão da experiência humana e das artes" (DIAS, 2013, p. 24). Ressaltamos, junto a Dias (2013, p. 26), "a arte como espaço, objeto e sujeito construtor de conhecimentos e saberes tanto para o campo das artes quanto para a área educacional".

Nesse sentido, esta pesquisa tem como foco a trajetória de um artista, pesquisador e professor que poetiza a partir de suas experiências de vida. Os dados são seus percursos poéticos, nos quais o corpo é fotografado de forma a pictorar suas aspirações investigadas no processo de formação estética docente. "Ao considerar uma docência que em sua prática de garimpar se deixa afetar pelas heterogeneidades, e uma aprendizagem pelos signos, fez-se necessário pensar como tais processos foram ocorrendo" (NEUSCHARANK, 2015, p. 10). Assim, o fazer artístico está articulado ao fazer pesquisa e compreender-se professor.

São aportes teóricos, neste estudo, Cohen (2007) e Duenha e Nunes (2017) nas discussões sobre a presença do corpo e a performance $a r t^{2}$. Percebemos que a arte da performance é um campo vasto, o qual vem sendo explorado na contemporaneidade por artistas, pesquisadores/pesquisadoras e professores/professoras. Ao aproximarmos a performance art da formação estética docente, buscamos por um estesiar-se para elaborar poeticamente signos (BARTHES, 2018) em experiências estéticas.

O encontro com a performance art, nesta investigação, dá-se com a artista Marina Abramović, a qual usa seu corpo como suporte na arte. Ela nasceu na década de 1940, na cidade de Belgrado, capital da Sérvia (ABRAMOVIĆ, 2017), e é um ícone na linguagem da performance. Sua produção apresenta o potencial do corpo como suporte e elemento da

\footnotetext{
2 Performance art: expressão cênica que advém de artistas plásticos. Uma linguagem híbrida, que se coloca em um limite entre as artes plásticas e as artes cênicas (COHEN, 2007).
} 
criação performática. A relação de presença corporal, espaço, tempo e objetos performáticos estão no centro da pesquisa de Abramović (MANTILLA, 2014). Nas performances de Abramović, observamos a intencionalidade do corpo por este possuir força, energia e presença e ser levado extremo para desenvolver suas propostas em arte.

Hélio Oiticica e Artur Barrio, artistas brasileiros, são referências artísticas que se relacionam a esta pesquisa, mobilizando nossos corpos, nossos modos de investigar. A vida de Hélio Oiticica (1937-1980) é marcada pela indisciplina em suas proposições estéticas. Foi um artista experimentalista que vivenciou linguagens em arte para produzir obras que dialogassem diretamente com o público. Um personagem sui generis para nossa época, diante de condições existenciais padronizadas (BRAGA, 2013). Já Artur Barrio nasceu em Portugal, em 1945. Veio para o Brasil no início de sua vida. Vive entre Rio de Janeiro, Salvador e Lisboa. É um artista singular, cuja trajetória privilegiou um circuito alternativo de arte. Tem por identidade uma produção anárquica (SARDENBERG, 2011). Esses artistas inspiram-nos e permitem-nos pensar em materialidades e processos poéticos, cuja presença do corpo é marcada pelos signos, tornando-se "verdadeiramente espectro" (BARTHES, 2018, p. 20).

A poiésis é a "noção que designa, genericamente, a aptidão para a criação, para a inauguração de sentidos que são e estão no criado como conteúdo (sentido) e expressão (realização), ao mesmo tempo" (SOUZA, 2007, p. 87). Ela vem a resultar na mobilização do corpo, que desenvolve reverberações estéticas na pesquisa em arte, dialogando com a docência. A relação com a teoria da arte, com os artistas, com o nosso tempo, com a vida e com o que se vivencia na docência e na pesquisa são algumas das reverberações que marcam essa poética. $\mathrm{O}$ a/r/tógrafo não é neutro ao seu tempo, ao seu espaço, ao seu contexto. Ele vive e pulsa o que está ao seu redor.

A poiésis tem por suporte o corpo em performance art, que se expande estabelecendo relações com o tempo e o espaço e abrindo caminhos para investigar formas de expressão, como o studium, "que não quer dizer, pelo menos de imediato, 'estudo', mas a aplicação a uma coisa, o gosto por alguém, uma espécie de investimento geral, ardoso, é verdadeiro, mas sem acuidade particular" (BARTHES, 2018, p. 27). Se o ato de criar pode estar conectado a trazer à tona novos significados, nesse processo, ressignificase o corpo e as materialidades para permitir múltiplos sentidos de aproximação com a arte e com a pesquisa. Ainda sobre o processo criativo, elucidamos que criar é dar uma nova forma àquilo que pretendemos investigar (OSTROWER, 2007). 


\section{dois - a poiésis e a pesquisa}

A poiésis, segundo Heidegger (2006) em A origem da obra de arte, promove o entendimento desta pesquisa. Para o autor, a poiésis não é um inventar do nada, sem contexto: "O que a poiésis como projeto iluminante desdobra no desvelamento e pré-lança no traço-cisão da figura é o aberto que a deixa acontecer e certamente de jeito que agora o aberto somente no meio do ente traga este para o iluminar e o ressoar" (HEIDEGGER, 2006 , p. 36). Isso em uma perspectiva em que o acontecimento se torna questionável na essência da poiésis (HEIDEGGER, 2006). Essa essência é experienciada e "conservada como algo digno de questão que antes de tudo é para [...] ser pensada" (HEIDEGGER, 2006, p. 36).

Nosso desejo poético almeja o deslocar-se e pôr-se a poetizar para, assim, [in]completar as respostas e gerar questionamentos na essência poética. O encontro com a arte também completa nossas incertezas sobre sua essência: "A hipótese mais plausível é que o termo 'arte' não é passível de ser definido, não apenas ao nível do que é visível, mas também ao nível relacional e não visível" (WARBURTON, 2007, p. 137). Os disparadores em arte que pertencem à consciência sensível do processo possibilitaram desenvolver as visualidades de Dilaporal, que evidenciaram a sensibilidade e a formação estética docente.

As configurações em momentos sensíveis de poetização põem o corpo a garimpar e poetizar no pesquisar. Não há sentido sem os sentidos (DUARTE JR., 2001). O corpo do a/r/tógrafo mobiliza-se em produzir arte para experienciar os processos poéticos que aderem ao uso da performance art, fotografia e edição gráfica, para compor o seu repertório estético e sensível.

Compreendemos que muito da poiésis, aqui investigada, nasce dos signos apresentados pelo corpo do a/r/tógrafo, que, muitas vezes, quis/quer vociferar suas inquietações ou sentimentos que foram calados e ficaram guardados, como

uma espécie de extracampo sutil, como se a imagem lançasse o desejo para além daquilo que ela dá a ver: não somente para 'o rosto' da nudez, não somente para o fantasma de uma prática, mas para a excelência absoluta de um ser, alma e corpo intricados (BARTHES, 2018, p. 53).

"Para alguns artistas, a partir desse momento não basta uma arte que retrate o corpo, ou que seja produzida sobre o corpo; ela tem que ser produzida com o corpo" (PIRES, 2005, p. 87). Em nossos estudos, observamos que o corpo "carrega subjetividades, memórias, marcas, dores, excitações, vibrações, mutações, sons e formas, 
desafia-se a percorrer o caminho de criação artística para materializar o sensível em visualidades" (PERUZZO; GOTTARDI; CARVALHO, 2018, p. 55).

Nesta experiência poética, a performance art é o disparador criativo. O corpo transforma-se no suporte para encontrar em si o punctum. "O punctum de uma foto é esse acaso que, nela, me punge (mas também me mortifica, me fere)" (BARTHES, 2018, p. 29). Nesta investigação, o corpo estesiado autoconduz-se ao encontro de puncta a partir de estímulos próprios e externos, os quais nascem de reflexões mentais durante o processo poético e são absorvidos pela carne. Não há um controlador da movimentação, mas, sim, um permitir dos desejos e das vontades de comunicar aquilo que sua matéria presente quer expressar.

Assim sendo, o indício de criação visual surge aqui com o recurso da fotografia. Na geração de visualidades, a câmera foi posicionada para registrar as poses de livre expressão construídas ao acaso durante a performance art, quando se registraram ações do corpo, lugares, estados e materialidades. Como em um rito, o desenvolver do caminhar aqui explorado perpassou o tempo e o espaço e perdeu-se no tempo, não viu a hora passar, pois "o tempo não está no tempo, o tempo não tem tempo" (DUFRENNE, 1969, p. 202). A poiésis acontece e estabelece situações racionais e não racionais em momentos organizados por questões técnicas e, em outros, pela expressão do corpo na relação subjetiva consigo mesmo. As imagens geradas no processo são a base para um revisitar da poiésis e revelam o detalhe "dado por acaso e para nada" (BARTHES, 2018, p. 42), como um jogo subjetivo (corpo do corpo pensante) que se autossubjetiva, para ferir a si mesmo.

A elaboração poética tem por conexão o repertório estético em arte do sujeito que descobre artistas e obras. As vivências na formação docente transbordam e possibilitam um olhar subjetivo na poiésis. O corpo, que anteriormente foi material para a poetização performática de visualidade, pôde observar a sua imagem e estabelecer outros lugares para a criação. O olhar percorre as fotografias e desencadeia a memória corporal do momento performático; e, dessa memória, surgem possibilidades poéticas. A relação poética de Abramović, Oiticica e Barrio tornam-se parte da composição, e "os signos não estão enquadrados apenas nesses espaços, estão em devir, em relações de afetos e de vida que pedem passagem" (NEUSCHARANK, 2015, p. 11). Os signos são sentidos e expressados pelo próprio corpo. Sentimentos e sensações são expurgados por esse corpo durante a poiésis, e rastros de inspirações surgem no produto visual. 
Com Abramović, identificamos a presença do corpo no espaço, deslocado por um universo seu, como na obra The House With The Ocean View ("A casa com vista para o mar"), na Figura 02. Nessa performance, Abramović mostra-nos a vida cotidiana dentro de uma casa e o quão sutil essa vida pode ser. Dilaporal traz o seu cotidiano de modo a apresentar o percurso da vida em espaços de uma residência, ao desfazer-se da própria carne.

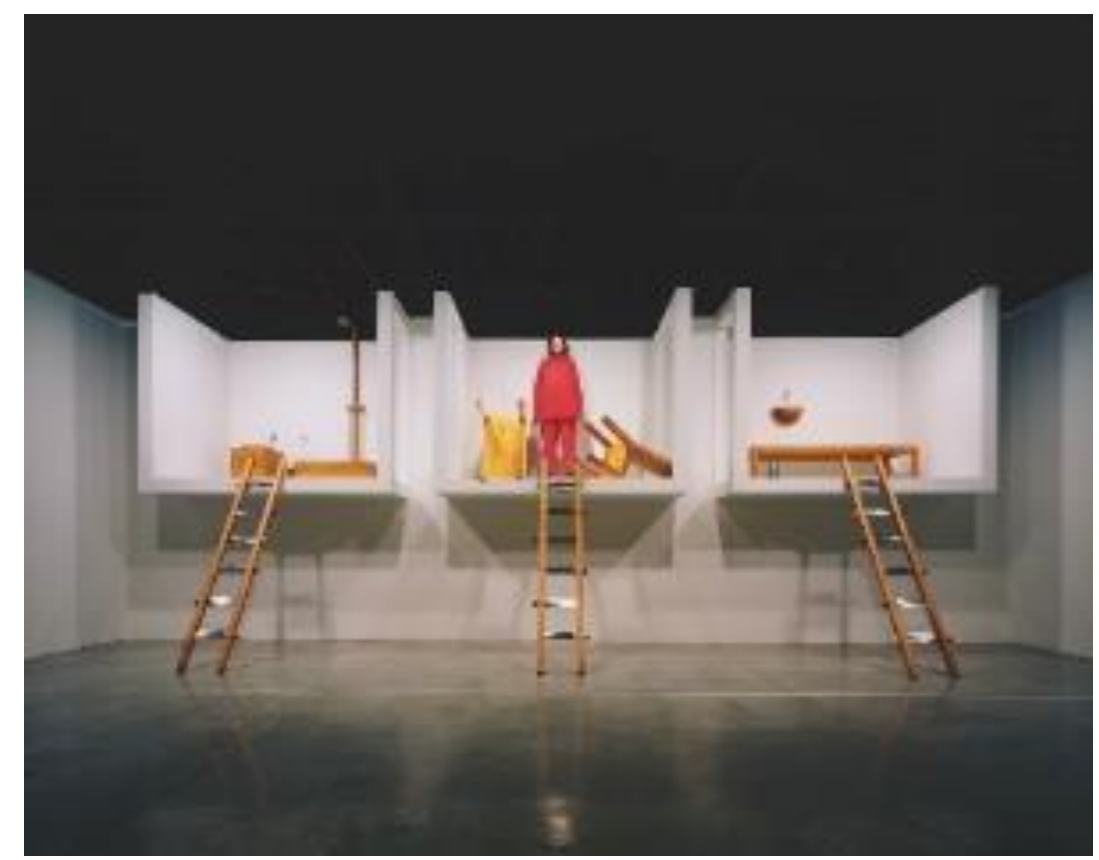

Figura 02: Performance The House With The Ocean View de Marina Abramović (2002) Fonte: FONDAZIONE PALAZZO STROZZI, $2018^{3}$

O encontro com o artista Artur Barrio e suas produções chama nossa atenção para a utilização de materialidades efêmeras, como a carne. As obras de Barrio geram estímulos, e, por vezes, no percurso poético desta pesquisa, o corpo absorve materialidades efêmeras e cria ligações, pois sua vida é efêmera. Em Dilaporal, o uso da máscara de carne faz referência à obra Livro de Carne (Figura 03) de Artur Barrio.

\footnotetext{
3 Disponível em: <https://www.palazzostrozzi.org/speciali/the-house-with-the-ocean-view2/?lang=en\&idmostra=8813>. Acesso em: 17 abr. 2019.
} 


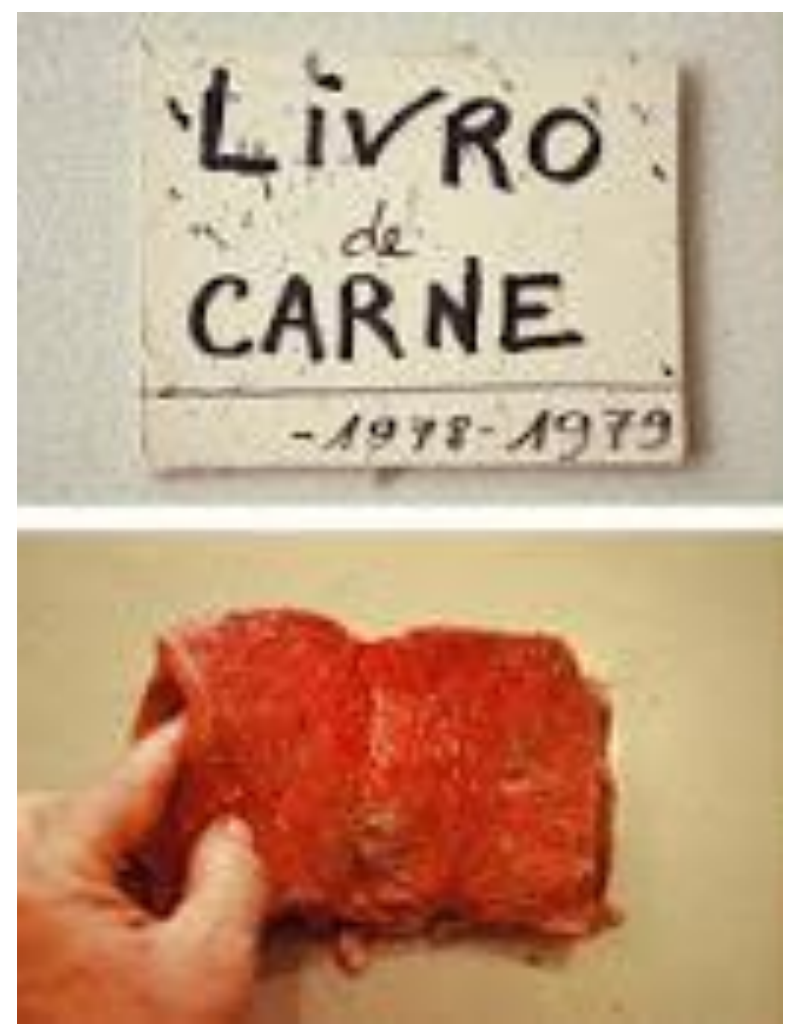

Figura 03: Livro de Carne de Artur Barrio (1978-1979) Fonte: Artur Barrio, 2011

Oiticica traz-nos sua dinâmica do espaço e a apropriação do próprio objeto artístico, como o Parangolé, que ultrapassa a linha do bidimensional para o tridimensional. Na década de 60, Oiticica descobriu, na periferia e no samba, uma experiência de êxtase, a qual ele nomearia de Parangolé (Figura 04).

A relação da obra com o corpo seria, então, criada. Segundo Braga (2013, p. 22), "[o] parangolé não é uma capa a ser trajada, mas uma extensão do corpo de quem a veste, como órgão novo, capaz de captar para o corpo, e em conjunto com o corpo, algo que ele não perceberia sozinho". Em Dilaporal, a máscara de carne ganha essa dinâmica do Parangolé. O objeto máscara com o corpo é "suficientemente crítica para inquietar" (BARTHES, 2018, p. 36). Para Barthes (2018, p. 35-36), "ela quer sentido, mas ao mesmo tempo quer que esse sentido seja cercado de um ruído [...] a foto cujo sentido (não digo o defeito) causa muita impressão é logo desviada; é consumida esteticamente, não politicamente".

\footnotetext{
${ }^{4}$ Disponível em: <http://arturbarrio-trabalhos.blogspot.com/2011/04/livro-de-carne-1978-1979.html>. Acesso em: 17 abr. 2019.
} 


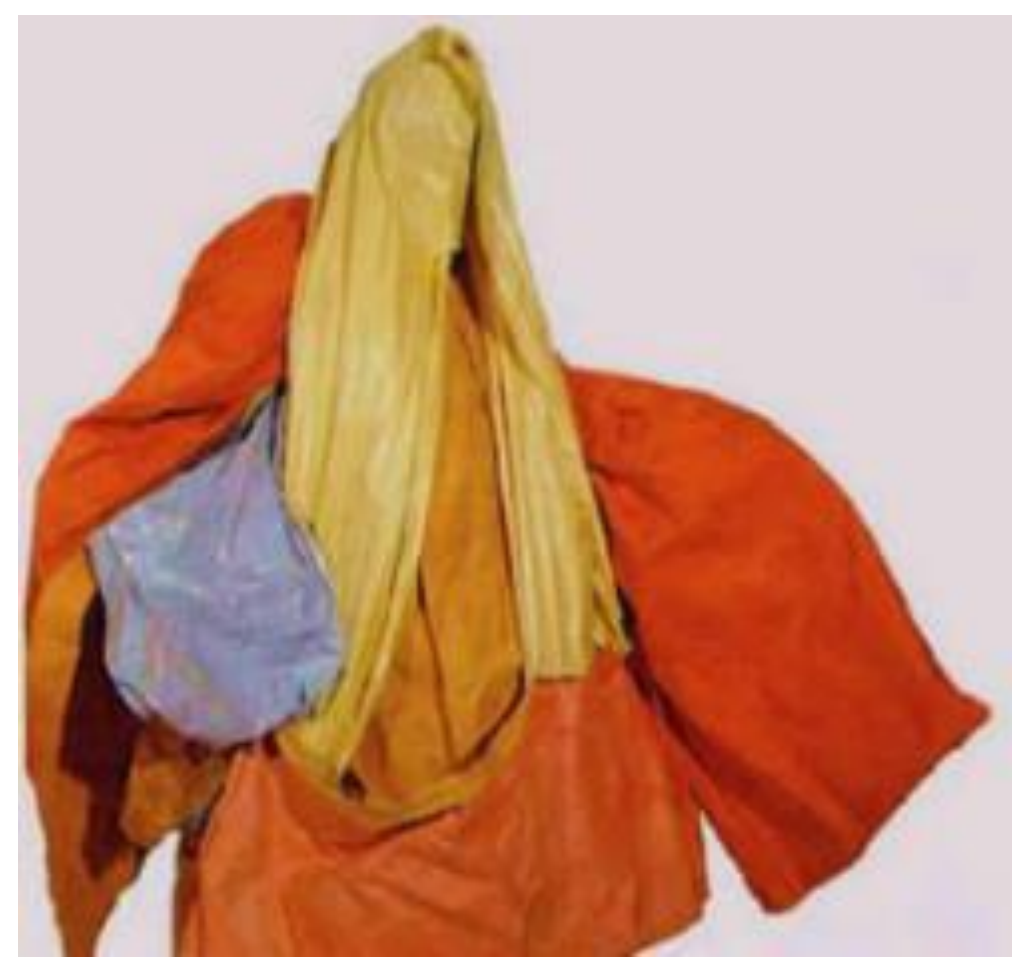

Figura 04: Parangolé de Hélio Oiticica (1964)

Fonte: ENCICLOPÉDIA ITAÚ CULTURAL. Parangolé P1, Capa 1, $2017^{5}$

Esses encontros só foram possíveis na poiésis quando paramos para analisar as obras The House With The Ocean View, Livro de Carne, Parangolé e os artistas mencionados. Isso nos permitiu observar punctuns e studiuns que poderiam compor o processo poético, nos propiciando reconhecer o corpo como potência de criação na arte, bem como dimensioná-lo no processo de formação estética docente. Nele,

o acaso dos encontros é que pode garantir a necessidade daquilo que é pensado, que pode garantir a decifração dos sentidos portados pelos signos e que a vida comunicou através de uma impressão material, porque é descoberto pelas sensações (NEUSCHARANK, 2015, p. 68).

A poiésis mobiliza inspirações e materialidades para a criação visual. Com um caráter de expansão do corpo e consciência em si mesmo, a performance art funciona como mecanismo de acesso a sensações provocadas por estímulos visuais e táteis e intensidades oscilantes no processo poético nas artes visuais, os quais podem variar de acordo com a disponibilidade do pesquisador. Esse campo, expandido para a experiência estética no corpo, implica a ampliação da percepção de que o docente que também pesquisa é motivado e vem a sentir necessidade do fazer artístico em processos de ensino. Dessa forma, o docente experimenta ser criador de percursos de criação em arte que

${ }^{5}$ Disponível em: <http://enciclopedia.itaucultural.org.br/obra66394/parangole-p1-capa-1>. Acesso em: 17 abr. 2019. 
constroem saberes, desenvolvendo percepções estéticas em sua prática junto aos estudantes (CARVALHO; IMMIANOVSKY, 2017).

Em nossas pesquisas, concordamos com Duenha e Nunes (2017) quando apontam que há um corpo presente contaminado por convites subjetivos feitos ao corpo em processos poéticos para, assim, estar com o outro e desencadear a sensibilidade no corpo - seja essa sensibilidade nos estudantes, direcionados no fazer artístico, seja ela na busca da potência do corpo sensível em sua formação estética com o mundo. Falamos sobre isso, pois não conseguimos visualizar um corpo não sensível em relação a outros corpos. 0 corpo sensível absorve arte, vive arte, produz arte para se transbordar e alcançar outros corpos.

A poiésis dá-se com o corpo presente (desde que este se permita), e as técnicas possibilitam que o corpo se desnude e navegue em constância para criar possíveis visualidades em um espaço/tempo que só as vivências em experiências poéticas e estéticas podem proporcionar. O corpo em expansão recruta as dimensões invisíveis que podem resultar em arte.

\section{três - Dilaporal}

A palavra "dilaporal", nesta pesquisa, faz parte da criação poética desenvolvida na investigação. Para compreender:

\section{DILA/PORAL}

DILA: Dilatação

PORAL: Corporal.

O dilaporal origina-se do percurso poético na formação do artista/professor (que faz arte e ensina). Entendemos que a "dilatação compreende o trabalho sobre si mesmo ao ampliar o modo de perceber as dinâmicas do movimento corporal" (PERUZZO, GOTTARDI; CARVALHO, 2018, p. 56).

Nesta análise, absorvemos o punctum - detalhe (BARTHES, 2018). O punctum conecta-se diretamente ao tratamento do dilaporal, cujas forças de expansão são apresentadas como base da Dilatação Corporal utilizada nos estudos de Eugenio Barba (1994). Desse modo, buscamos os detalhes nos registros fotográficos realizados na performance e percebemos que, na poiésis, a máscara é a subjetivação do punctum. Em 
Dilaporal, a máscara esconde, mas, ao mesmo tempo, se expande na composição; dilatase e traz à tona a composição da cena.

De acordo com Barba (1994), o corpo em estado de dilatação encontra-se expandido, aquecido, reverberando presença em seu ato performático, o que permite um sentir estético na produção, com uma amplitude que ultrapassa os estados de preservação física e de ação. $O$ autor permite-nos compreender que o ator, ao atingir um corpo dilatado em seu processo poético, cria conexões diretas com o interlocutor na obra. Sendo sucinto, a dilatação é uma técnica corporal explorada no teatro que constrói um corpo presente em relação ao espaço de cena (BARBA, 1994).

Partimos do pensamento de que a dilatação corporal se relaciona diretamente ao punctum. Assim, ao contemplar a poiésis dilaporal, os olhos do espectador, como primeiro canal de comunicação, podem capturar visualmente a dilatação. Nesse processo poético, o olho identifica e transfere para a carne o sentido que a consciência não consegue descrever.

Quando temos o corpo em performance na poiésis, este tenderá a vivenciá-la para conhecer suas experiências estéticas. O corpo embebido ${ }^{6}$ na poiésis buscará, em sua interioridade e exterioridade, a experiência aproximada; desse modo, em Dilaporal, as poses, a composição da cena, os materiais, a ação performática e a expressão são determinados pela forma que o corpo encontra ao se expressar.

Em uma relação fisiológica, o conceito de propriocepção (FERNANDES, 2016), estudado na anatomia humana, responderá pelas ações dos músculos do corpo, reconhecendo seus alcances como o caminhar ou a força para bater palmas. Essa construção do corpo em estados performáticos aproxima-se das obras investigadas e, de algum modo, acaba propondo estímulos poéticos em que os músculos do corpo, a frequência cardíaca e a temperatura corporal são fatores experienciados na poiésis dilaporal.

Para que isso seja possível, precisamos retirar o valor simbólico do corpo e usar a fotografia como recurso da poiésis, que irá criar uma conectividade com a expansão que o corpo necessita. Ainda sobre a fotografia em Dilaporal:

[...] a foto do ser desaparecido vem me tocar como os raios retardados de uma estrela. Uma espécie de vínculo umbilical liga a meu olhar o corpo da coisa fotografada: a luz, embora impalpável,

\footnotetext{
${ }^{6}$ Na poiésis dilaporal, um corpo embebido transborda as técnicas e as materialidades durante a execução poética. Intuições e subjetivações constituem o processo, e os estados corporais são encontrados com o uso da técnica de dilatação do corpo.
} 
é aqui um meio carnal, uma pele que partilho com aquele ou aquela que foi fotografado (BARTHES, 2018, p. 70).

Sendo a fotografia parte da poiésis dilaporal, a não utilização desse recurso não concretizaria o registro da expansão do corpo, o qual é evidenciado no processo poético. Por esse motivo, o corpo é tema e suporte na produção das visualidades encontradas no garimpar (NEUSCHARANK, 2015) dos caminhos conceituais explorados na formação estética docente.

Ainda conversando com Barthes (2018, p. 44): "Há uma expansão do punctum (menos proustiana): quando, paradoxo, ao mesmo tempo que permanece um 'detalhe' preenche toda a fotografia". Uma dilatação só é possível em processos poéticos em que há um envolvimento íntegro do docente, ciente de seu processo poético e entregue a ele, para que os sentidos do corpo aflorem em sua carne e tragam à tona um diálogo informal com a arte.

\section{quatro - o processo da poiésis}

Temporalmente, dividiu-se o processo da poiésis nas seguintes etapas: a) performance art; b) fotografia ou vídeo; c) edição gráfica; d) impressão sobre suporte; e) novos signos. Os caminhos poéticos da pesquisa são ressignificados para apresentar as visualidades resultantes na investigação. Estimula-se o corpo a produzir aquilo que a ele é permitido como matéria efêmera e sensível. Parte-se, assim, de ações performáticas para apresentar o processo da poiésis. Nesta seção, apresentamos uma sistematização do processo de investigação das potencialidades estéticas e visuais do corpo como tema, suporte e metáfora.

a) Performance art: A performance art conduz o corpo. Com o corpo presente, os poros são abertos, a atenção é dobrada, e o tempo presente concretiza a ação. A ação pode criar caráter ritualístico, como em Dilaporal, cujos materiais e recursos foram disponibilizados. Também se estabeleceu um roteiro prévio, mas esse serviu apenas como ponto de partida. Os limites são dissolvidos, e a relação estética passa a ser ritualizada na performance, deslocando as dimensões da interação (COHEN, 2007). Por estímulos próprios não racionais, deixa-se levar o corpo para conseguir tocar ou aproximar o que o momento pode Ihe ofertar. Nunca há uma ideia de fim; o próprio corpo diz quando deve começar e terminar.

b) Fotografia ou vídeo: Para registro poético, a câmera é potência na geração de 
visualidades. Neste caso, a performance art foi registrada fotograficamente com o uso do recurso timer. Em situações de uso de vídeo, a performance é gravada, e, posteriormente, a edição é feita, caso necessário. Frames do vídeo também podem ser utilizados como recurso poético.

c) Edição gráfica: Em Dilaporal, utilizou-se um software específico para edição, acrescentando efeitos, recortes, entre outros recursos possíveis. Na atualidade, o uso do smartphone permite a utilização de diferentes aplicativos que podem ser utilizados como recurso de edição gráfica. Laboratórios de informática também são espaços que podem potencializar esse olhar para a arte.

d) Impressão sobre suporte: $A$ escolha do suporte pode determinar questões estéticas da produção e pode sofrer alterações. A investigação de outros suportes permite reconhecer as diferentes formas da produção poética. Esse é um campo de investigação que possibilita o reconhecimento das diferentes materialidades que a arte absorve. Ao explorar diferentes suportes, o repertório estético pode ser ampliado, expandindo o modo de fazer arte. O suporte selecionado para impressão dos resultados poéticos é a impressão digital sobre tecido, em função da qualidade, textura e facilidade de manuseio.

e) Novos signos: É momento de ressignificar. Pode-se fazer imbricações com as produções anteriores, procurando novos sentidos ou novas maneiras de chegar a resultados parecidos ou distintos, com métodos diferentes ligados diretamente à semiótica, desafiando, assim, a compreensão das fronteiras entre vida e arte.

Um Signo, ou Representamen, é um Primeiro que se coloca numa relação triádica genuína tal com um Segundo, denominado seu Objeto, que é capaz de determinar um Terceiro, denominado seu Interpretante, que assuma a mesma relação triádica com seu Objeto na qual ele próprio está em relação com o mesmo Objeto (PIERCE, 2010, p. 63).

A representação, segundo Pierce (2010, p. 61), é "[e]star em lugar de, isto é, estar numa tal relação com um outro que, para certos propósitos, é considerado por alguma mente como se fosse outro". Assim, o signo permite que se crie, na mente daquele que interpreta, as narrativas sobre o objeto. "A foto é literalmente uma emanação do referente. De um corpo real, que estava lá, partiram radiações que vêm me atingir, a mim, que estou aqui" (BARTHES, 2018, p. 70). A foto, como signo, permite que o olhar daquele que interpreta construa suas narrativas. Conforme a poiésis é explorada, de acordo com Seligmann-Silva (2019), o signo passa a ser parte do corpo na contemporaneidade, que expressa suas próprias inquietações sobre a vida. No desenvolver da construção de 
narrativas, o processo poético abraça e explora técnicas e intuições na produção visual, reconhecendo o potencial semiótico que a imagem possui.

O processo poético buscará ressignificar os estímulos criativos no corpo para gerar signos nas investigações, subjetivamente ou não. Essas são possibilidades que aparecem no processo durante a descoberta do modo de poetizar. Vale ressaltarmos que todo o processo precisa ser evidenciado e compartilhado, por compor esta pesquisa. O encontro com Barthes (2018) é estudado e evidenciado na poiésis, como a construção de uma máscara de carne usada como parangolé durante a performance art. Do que valeria todo o estudo empregado sobre a poiésis se não houvesse a possibilidade de compartilhar todos os pontos explorados no caminho? Os signos em: [ ] as palavras às vezes [ ] dizem aquilo que nem sempre queremos saber ou não. Do mesmo modo [ ] da mesma maneira. ${ }^{7}$ (SAUSSURE, 1985).

\section{cinco - resultados visuais}

Ao olharmos o caminho poético e de pesquisa, reconhecendo a sensibilidade e a subjetividade do sujeito no caminho, temos as visualidades expostas a seguir, produzidas como resultado poético da pesquisa. O projeto visual é uma série composta por quinze obras, mas, aqui, apresentamos somente quatro obras resultantes dessa imersão. 0 projeto foi aprovado por meio de edital de ocupação das exposições temporárias do período de 2019 no Museu de Arte Contemporânea de Mato Grosso do Sul, em Campo Grande.

Dilaporal é antropofágico, corpo[carne] que come sua própria carne (sejam sentimentos ou emoções), o punctum que nos fere. Nosso corpo arbitrário, em seu cotidiano, revela seus estados sensíveis em meio a tantos questionamentos, registros, marcados na sua carne, que, em silêncio, tece a vida, voluntária ou involuntariamente por meio daquilo que é mais sagrado.

Percebemos que a poiésis de Dilaporal não se preocupa com um padrão definido, mas, sim, com o que um processo poético poderá apresentar. Na Figura 05, temos um autorretrato. A máscara de carne esconde a face, porém podemos observar a silhueta de uma outra face na sombra reproduzida ao fundo. A posição do corpo também predomina

\footnotetext{
${ }^{7}$ Os colchetes utilizados nessa frase estão abertos porque fechados e omitem as palavras para que o leitor venha a deduzir e/ou completar ou não a oração. Essa proposição busca mostrar o quanto as palavras podem ser arbitrárias em nossa relação com linguagem.
} 
na composição da cena, levando-nos a imaginar momentos pensativos. As marcas no corpo podem exprimir histórias e contextos culturais.

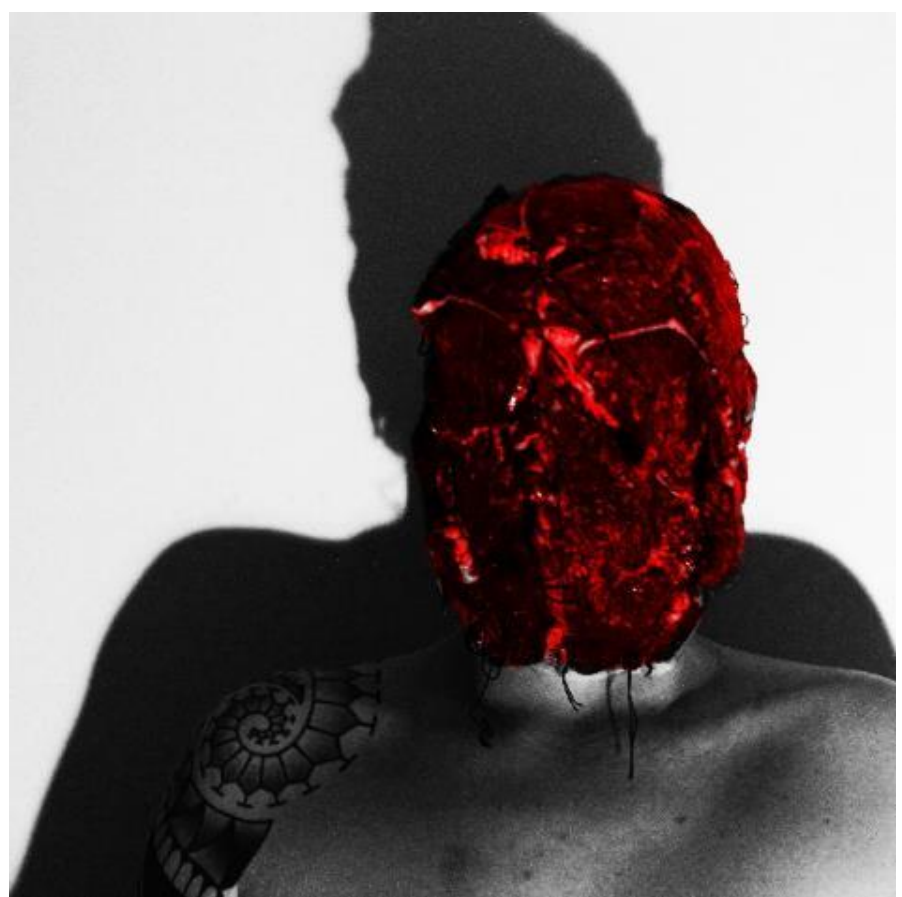

Figura 05: Obra que compõe a série Dilaporal | Técnica: Performance, fotografia e edição gráfica | Suporte: Tecido | Dimensões: 50x50cm | Ano: 2018 Fonte: Pedro Gottardi, 2018

Dilaporal é resposta de nossas vontades e experiências, que nos põem a poetizar e pictorar histórias de vida, sobre as quais nem sempre conseguimos falar. Na Figura 06, temos o corpo nu, mascarado, dentro de um carrinho de supermercado. A cor vermelha da máscara e o corpo disposto no carrinho podem conduzir à reflexão sobre o consumo de carne vermelha e sobre filosofias de vida cujos adeptos não consomem carne, como o veganismo. 


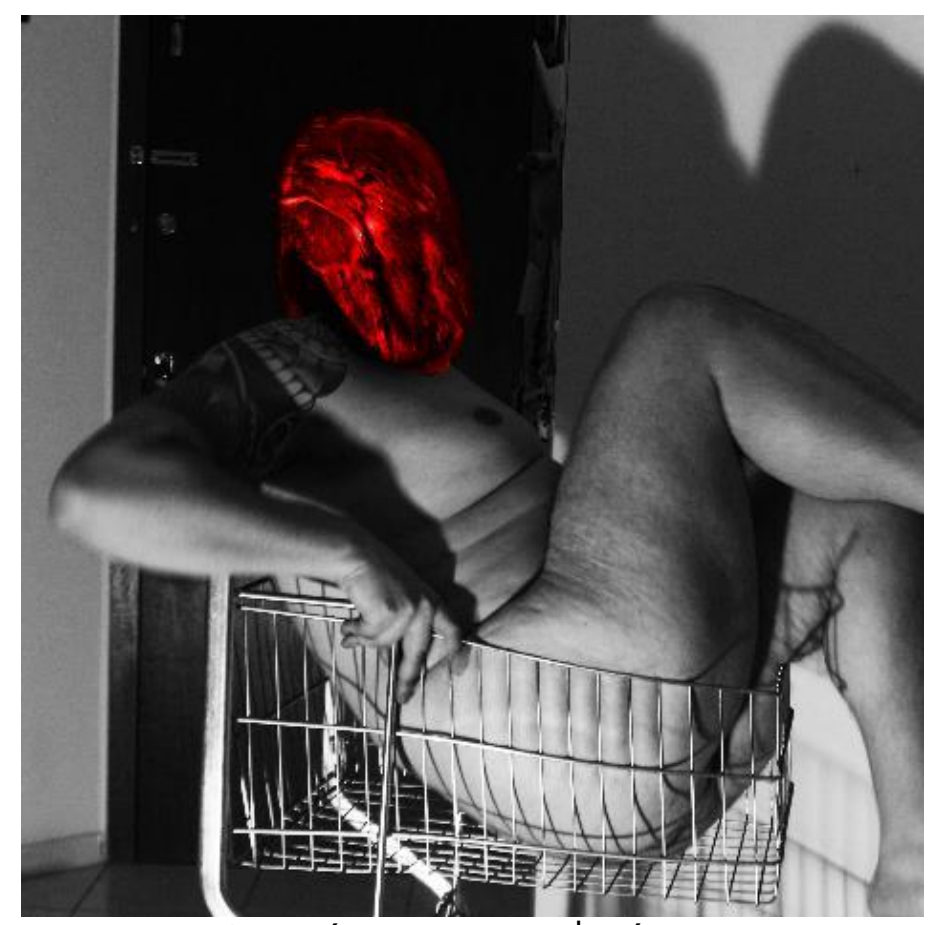

Figura 06: Obra que compõe a série Dilaporal | Técnica: Performance, fotografia e edição gráfica | Suporte: Tecido | Dimensões: 50x50cm | Ano: 2018

Fonte: Pedro Gottardi, 2018

Dilaporal é como Parangolé, ou como um corpo experimental, ou como um livro. $\mathrm{Na}$ Figura 07, a máscara não estava posicionada sobre a cabeça, mas a sua frente. O olhar predomina, e há uma tendência a observar a região do olho através da máscara.

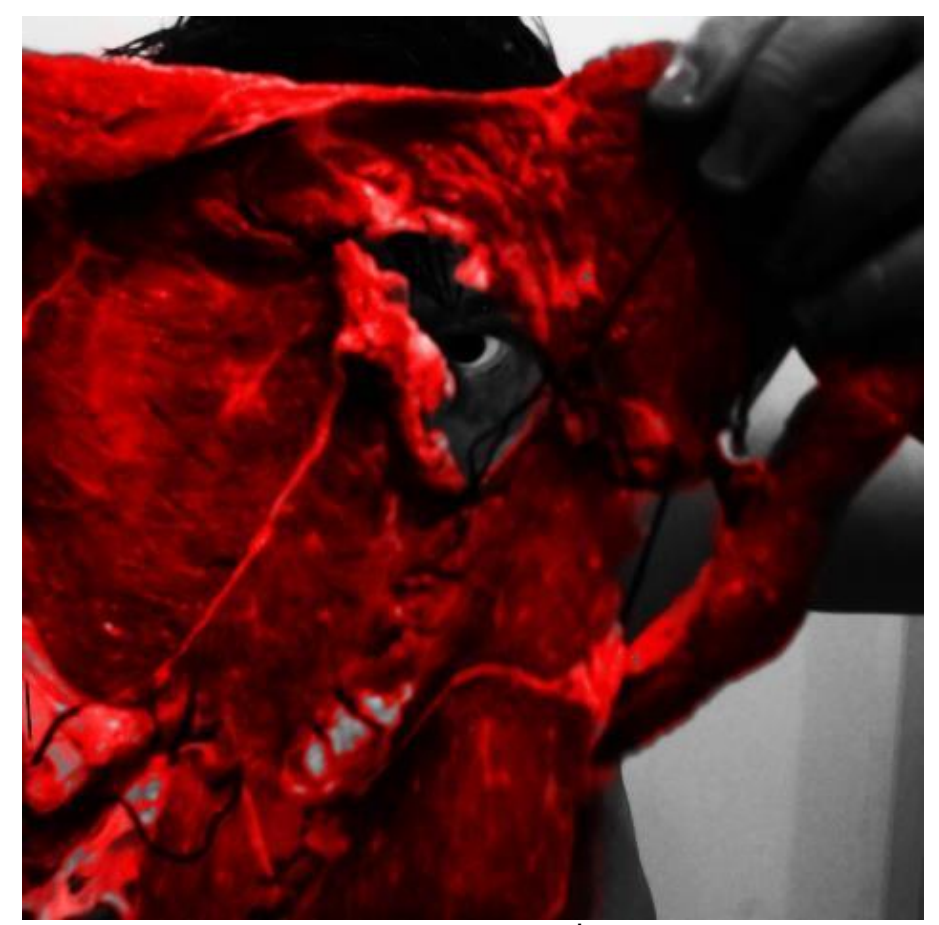

Figura 07: Obra que compõe a série Dilaporal | Técnica: Performance, fotografia e edição gráfica | Suporte: Tecido | Dimensões: 50x50cm | Ano: 2018

Fonte: Pedro Gottardi, 2018 
Dilaporal permite-nos pensar sobre o que somos e como somos; como gomo de tangerina virado ao avesso, cujo corpo do fruto é visível, saboreado e talvez mal digerido. Na Figura 08, temos o corpo em posição de leitura. Sua máscara não impede a leitura, e a cena parece-nos relatar o encontro com narrativas. A sombra do corpo ao fundo dá mais ênfase ao ato de ler, o punctum expande-se para as mãos.

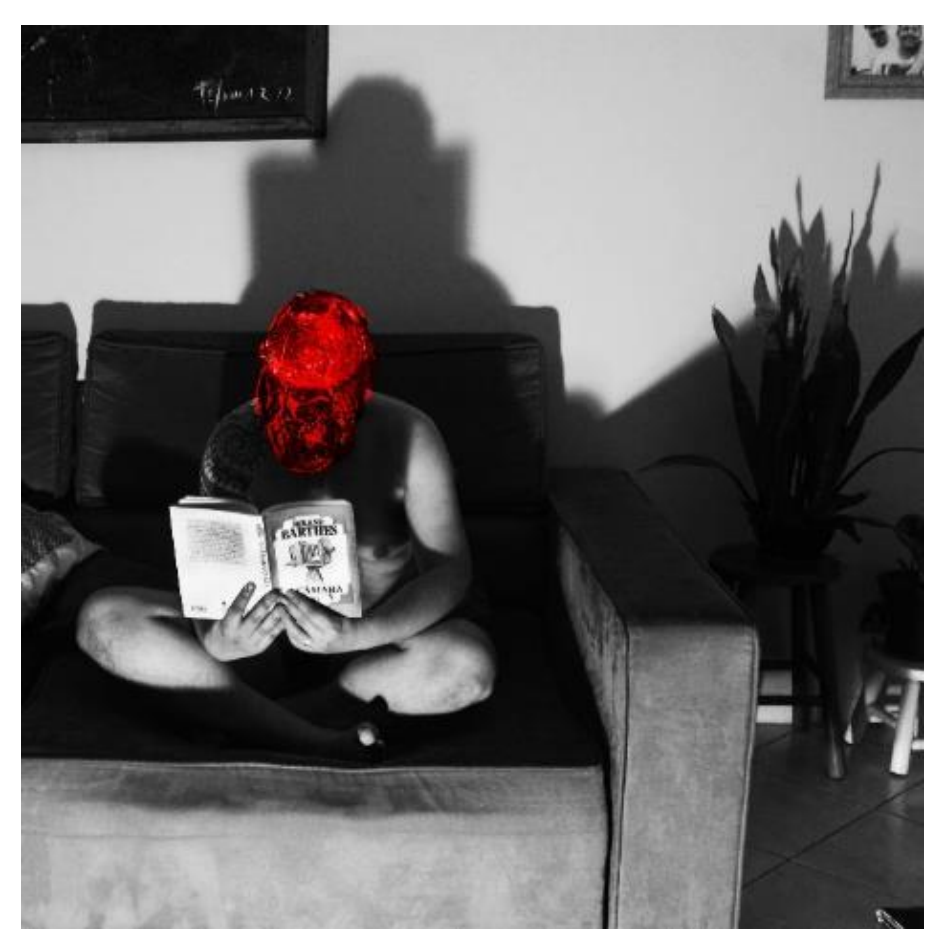

Figura 08: Obra que compõe a série Dilaporal | Técnica: Performance, fotografia e edição gráfica | Suporte: Tecido | Dimensões: 50x50cm | Ano: 2018 Fonte: Pedro Gottardi, 2018

\section{seis - conclusões}

Consideramos essas obras garimpagens de experiências estéticas do corpo do licenciando em sua formação estética docente.

Não se trata da docência ou da aprendizagem, mas de uma docência garimpeira, como de quem pensa nas suas ações sobre o produzir aprendizagens sobre o que encontra pelo caminho, pelo meio, o que a potencializa olhar para o informe, o heterogêneo. (NEUSCHARANK, 2015, p. 22).

Suas reverberações foram parte de suas reflexões estéticas na arte, na qualidade de artista/pesquisador/professor, que também se desloca a poetizar. Dessa maneira, não conseguimos desvincular as visualidades (obras) desenvolvidas neste estudo do nosso modo de pesquisar, pois este só foi possível em função da experimentação do ser 
artista/pesquisador/professor. Ao integrar os aportes teóricos no processo poético, este ganhou os registros necessários para imprimir visualmente as reflexões internas que um corpo pode apresentar.

Essas experiências puderam destacar que, independentemente de padrão estético ou técnica, o ato poético de um corpo poderá tomar rumos diferentes. As dimensões da produção em arte fazem parte da construção do sujeito que permite evidenciar suas potencialidades. Nesse sentido, "o corpo presente na dimensão do aqui-agora representa a concentração das potencialidades corporais para a criação artística" (PERUZZO; GOTTARDI; CARVALHO, 2018, p. 62).

Notamos que Dilaporal conversa com as obras de Marina Abramović, Hélio Oiticica e Artur Barrio, mesmo que, de partida, eles tenham tido por função o diálogo visual e conceitual, pois percebemos uma elaboração estética que se relaciona ao corpo do docente subjetivamente. "A subjetividade é compreendida como uma dimensão do sujeito, assim como a objetividade que, relacionadas dialeticamente no contexto social, produzem o sujeito" (MAHEIRIE, 2002, p. 37).

Compreendemos, com este estudo, que temos um corpo estético quando esse corpo vive a poiésis. O corpo do pesquisador, ao ser colocado em justaposição, sente-se confrontado, vai ao garimpo para escavar as preciosidades para, assim, lapidá-las em visualidades no seu processo de formação estética docente.

\section{Referências}

ABRAMOVIĆ, Marina. Pelas paredes: memórias de Marina Abramović. Rio de Janeiro: José Olympio, 2017.

BARBA, Eugenio. A canoa de papel: tratado de antropologia teatral. São Paulo: Hucitec, 1994.

BARTHES, Roland. A câmara clara: nota sobre a fotografia. 7. ed. Rio de Janeiro: Editora Nova Fronteira, 2018.

BRAGA, Paula. Hélio Oiticica. São Paulo: Folha de São Paulo; Instituto Itaú Cultural, 2013.

CARVALHO, Carla; IMMIANOVSKY, Charles. PEBA: a arte e a pesquisa em educação. Revista Reflexão e Ação, Santa Cruz do Sul, RS, v. 25, n. 3, p. 221-236, set./dez. 2017.

COHEN, Renato. Performance como linguagem: criação de um tempo-espaço de experimentação. 2. ed. São Paulo: Perspectiva, 2007.

DIAS, Belidson. A/r/tografia como Metodologia e Pedagogia em Artes: uma introdução. In: DIAS, Belidson; IRWIN, Rita (Org.). Pesquisa Educacional baseada em 
Arte: A/r/tografia. Santa Maria, RS: Editora UFSM, 2013. p. 21-26.

DIAS, Belidson; IRWIN, Rita (Org.). Pesquisa Educacional baseada em Arte: A/r/tografia. Santa Maria, RS: Editora UFSM, 2013.

DUARTE JR., João Francisco. O sentido dos sentidos: a educação (do) sensível. Curitiba: Criar Edições, 2001.

DUENHA, Milene Lopes; NUNES, Sandra Meyer. Presença que não se Faz Só: potências de afeto no ato de com-por entre corpos. Revista Brasileira de Estudos da Presença, Porto Alegre, v. 7, n. 1, p. 99-122, jan./abr. 2017.

DUFRENNE, Mikel. O Poético. Porto Alegre: Editora Globo, 1969.

\section{FERNANDES, Patrícia Vieira. A relação entre a informação proprioceptiva e a manutenção da postura. 2016.2 Disponível em:} <http://www.profala.com/artfisio5.htm>. Acesso em: 16 nov. 2018.

HEIDEGGER, Martin. A origem da obra de arte. Tradução Idalina Azevedo da Silva e Manuel Antônio de Castro. Rio de Janeiro: Faculdade de Letras - UFRJ, 2006.

MAHEIRIE, Kátia. Constituição do Sujeito, Subjetividade e Identidade. Nexin, São Paulo, v. 7, n. 13, p. 31-44, jun. 2002.

MANTILLA, Jesús Ruiz. Entrevista com Marina Abramović: 'Eu estou farta do ambiente econômico que rodeia a arte'. El País, Madrid, 28 maio 2014. Disponível em: <http://brasil.elpais.com/brasil/2014/05/27/eps/1401205816_492745.html>.

Acesso em: 25 nov. 2019.

NEUSCHARANK, Angélica. Uma docência pela Garimpagem: encontros com signos. 2015. 80 f. Dissertação (Mestrado em Educação)-Universidade Federal de Santa Maria, Santa Maria, RS, 2015.

OSTROWER, Fayga. Criatividade e processos de criação. 6. ed. Petrópolis, RJ: Vozes, 2007.

PERUZZO, Leomar; GOTTARDI, Pedro; CARVALHO, Carla. Dilatação corporal, performance art e a docência: um percurso de criação visual. Revista Digital do LAV, Santa Maria, RS, v. 11 , n. 3, p. 47-66, dez. 2018.

PIERCE, Charles Sanders. Semiótica. 4. ed. São Paulo: Perspectiva, 2010.

PIRES, Beatriz Ferreira. O corpo como suporte da arte: piercing, implante, escarificações, tatuagem. São Paulo: Senac São Paulo, 2005.

SARDENBERG, Ricardo. Arte contemporânea brasileira no século XXI: 10 artistas no circuito internacional. Rio de Janeiro: Capivara, 2011.

SAUSSURE, Ferdinand de. As palavras sob as palavras. In: SAUSSURE, Ferdinand de et al. (Org.). Textos Selecionados. 3. ed. São Paulo: Abril Cultural, 1985. p. 3-53.

SELIGMANN-SILVA, Márcio. Da representação para a apresentação. Cult, São Paulo, 2019. Disponível em: <https://revistacult.uol.com.br/home/da-representacao-para-aapresentacao/>. Acesso em: 29 abr. 2019. 
SOUZA, Jovelina Maria Ramos de. As origens da noção de poíēsis. Hypnos, São Paulo, v. 19, n. 13, p. 85-96, jul. 2007.

WARBURTON, Nigel. E Agora? In: (Org.). O que é a Arte. Lisboa: Bizâncio, 2007. p. $137-151$.

\footnotetext{
i Pedro Gottardi é mestrando em Educação pela Universidade Regional de Blumenau (FURB) e bolsista Capes (2019-2021). Graduado em Licenciatura em Artes Visuais pela FURB (2018). É artista plástico, performer, professor de Arte e integrante do Grupo de Pesquisa em Artes e Estética na Educação. Ainda, é conselheiro de Cultura em Blumenau/SC, gestão (2019-2021).

ii Carla Carvalho atua como professora no Programa de Pós-Graduação em Educação na Universidade Regional de Blumenau (FURB) e na graduação em cursos de Formação de Professores e Design. Possui graduação em Licenciatura Plena Em Educação Artística pela FURB (1998), mestrado em Educação pela Universidade do Vale do Itajaí (2003) e doutorado em Educação pela Universidade Federal do Paraná (2008). Líder do Grupo de Pesquisa Arte e Estética na Educação. Atualmente coordena o PROESDELicenciatura/FURB. Tem experiência na área de Educação, com ênfase em Educação, atuando principalmente nos seguintes temas: arte na educação, artes visuais, mediação cultural, estética na Educação e formação de professores.
}

Como citar esse artigo:

GOTTARDI, Pedro; CARVALHO, Carla. A poiésis Dilaporal: formação estética docente e performance art. Revista Digital do LAV, Santa Maria: UFSM, v. 14, n. 1, p. 26-46, jan./abr. 2021. 